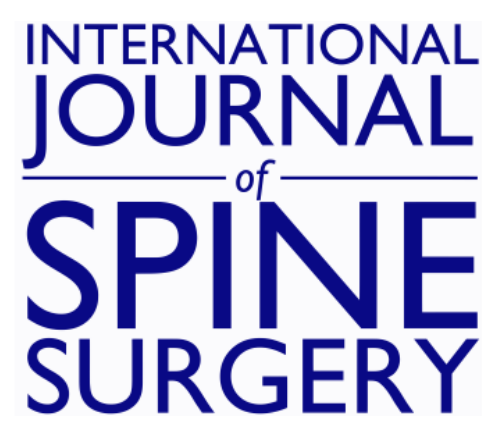

\title{
Posterior Dynamic Stabilization as a Salvage Procedure for Lumbar Facet Degeneration Following Total Disc Arthroplasty: Case report
}

Paul Khoueir and Michael Y. Wang

Int J Spine Surg 2007, 1 (4) 143-146

doi: https://doi.org/10.1016/SASJ-2007-0103-CR-R2

http://ijssurgery.com/content/1/4/143

This information is current as of April 26, 2023.

Email Alerts Receive free email-alerts when new articles cite this article. Sign up at:

http://ijssurgery.com/alerts

The International Journal of Spine Surgery

2397 Waterbury Circle, Suite 1,

Aurora, IL 60504, Phone: +1-630-375-1432 


\title{
Posterior Dynamic Stabilization as a Salvage Procedure for Lumbar Facet Degeneration Following Total Disc Arthroplasty
}

\author{
CASE REPORT
}

Paul Khoueir, MD, and Michael Y. Wang, MD

\begin{abstract}
Following an L5-S1 SB Charité disc III implantation, a 37-year-old female patient developed intractable radicular pain in the left $\mathrm{L} 5$ distribution. The patient underwent a minimally invasive foraminotomy, and her symptoms improved significantly. However, following recurrence of radicular pain, she showed signs of an L5-S1 facet degeneration and recurrent nerve root compression from hypertrophied synovium. A partial facetectomy was then performed to completely decompress the L5 root with supplemental posterior dynamic stabilization using a pedicle-based flexible titanium rod system. To date, the patient remains free of symptoms. Although posterolateral fusion would have been a viable option, the application of a posterior dynamic system permitted segmental motion preservation.
\end{abstract}

Key Words Disc arthroplasty, posterior dynamic stabilization, facet disease, revision surgery, complications, lumbar spine. SAS Journal. Autumn 2007;1:143-146. DOI: SASJ-2007-0103-CR-R2

\section{INTRODUCTION}

The goal of total disc replacement is to restore or maintain intervertebral spinal motion, thereby decreasing the incidence of adjacent segment degeneration and avoiding complications related to fusion. ${ }^{1-9}$ More than 15,000 implantations have been performed worldwide following introduction of the third-generation SB Charité total artificial disc (DePuy Spine, Raynham, Massachusetts). ${ }^{10}$ Based on cases reported in the European literature, more than $70 \%$ of these patients showed improvement in pain and function. ${ }^{11-14}$ In the United States, a prospective randomized multicenter clinical trial demonstrated that quantitative clinical outcome measures following lumbar total disc replacement with the Charité artificial disc were at least equivalent to anterior lumbar interbody fusion. ${ }^{10,15-18}$ The clinical success of the Charite artificial disc has also been associated with low reoperation rates. ${ }^{10}$ However, when failures do occur, surgical strategies that maintain intervertebral spinal motion make it possible to avoid complications related to arthrodesis.

\section{CASE REPORT}

History

A 37-year-old Caucasian female patient presented with a three-year history of debilitating low back pain that had been unresponsive to conservative measures. The patient's surgical history included an L5-S1 microdiscectomy for a disc herniation with L5 radicular pain and numbness, which were almost completely resolved at the time of her presentation. Her lumbar MRI and bone scan demonstrated severe degeneration of the L5-S1 disc with type 1 Modic changes.

The patient's preoperative imaging also did not reveal important facet disease, except for some asymptomatic postoperative changes

\section{Figure 1}

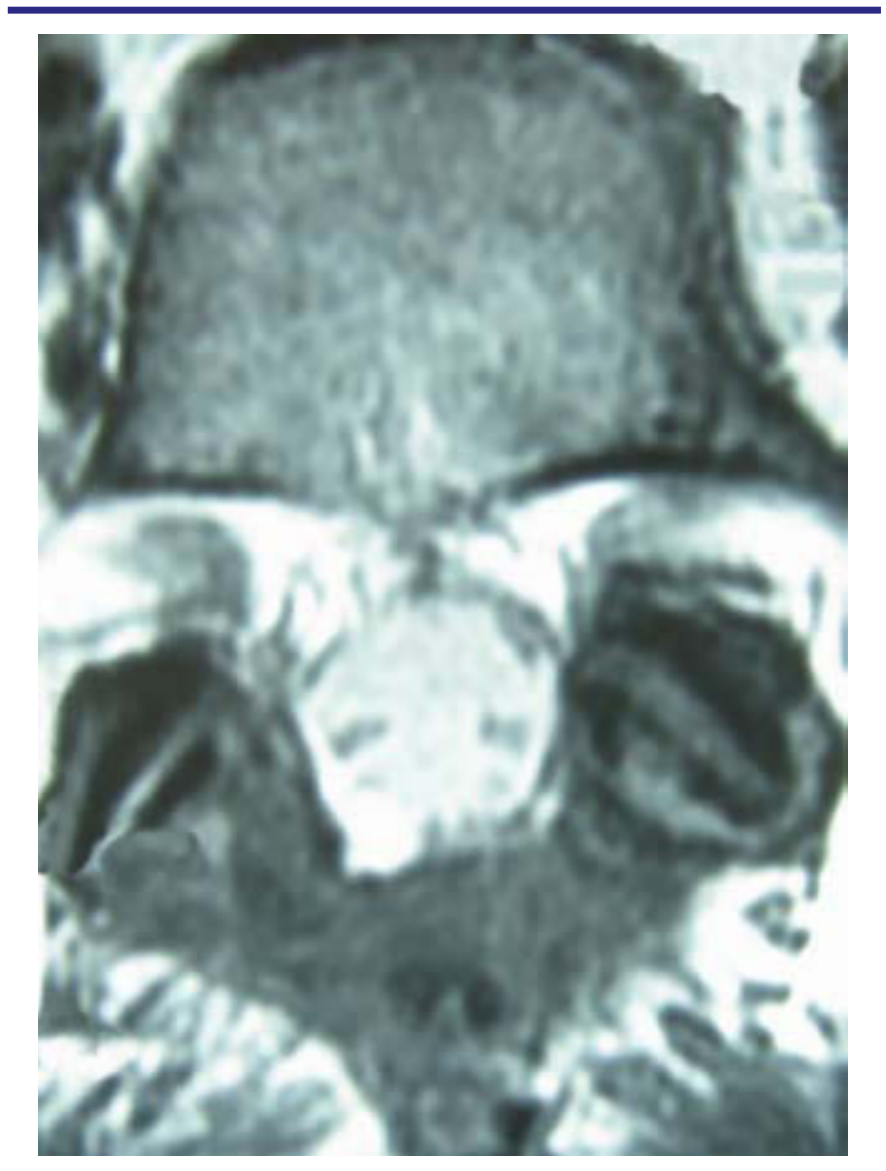

Axial view of a preoperative MRI showing changes due to a prior L5-S1 left hemilaminectomy with some degree of left facet degeneration. 
in the left facet associated with prior laminectomy (Figure 1). Therefore, a size four SB Charité III total disc replacement with 9.5 mm core (DePuy Spine, Raynham, Massachusetts) was implanted at the L5-S1 level. After implantation of the disc replacement device, the patient's low back pain abated remarkably. However, one month later, she began developing a left L5 radicular pain and numbness, for which she underwent extensive postoperative radiological testing. Anteroposterior and lateral radiography demonstrated proper positioning of the arthroplasty device (Figure 2). An MRI and CT-myelogram failed to show L5-S1 foraminal stenosis due to metal artifact from the disc arthroplasty device. After failing several months of extensive conservative management, the patient underwent an exploratory foraminotomy of the left L5-S1 foramen. Intraoperatively, the patient had left L5 nerve root entrapment due to hypertrophied synovium with no evidence of disc herniation, and during decompression every effort was made to preserve as much of the facet joint as possible.

\section{Figure 2}

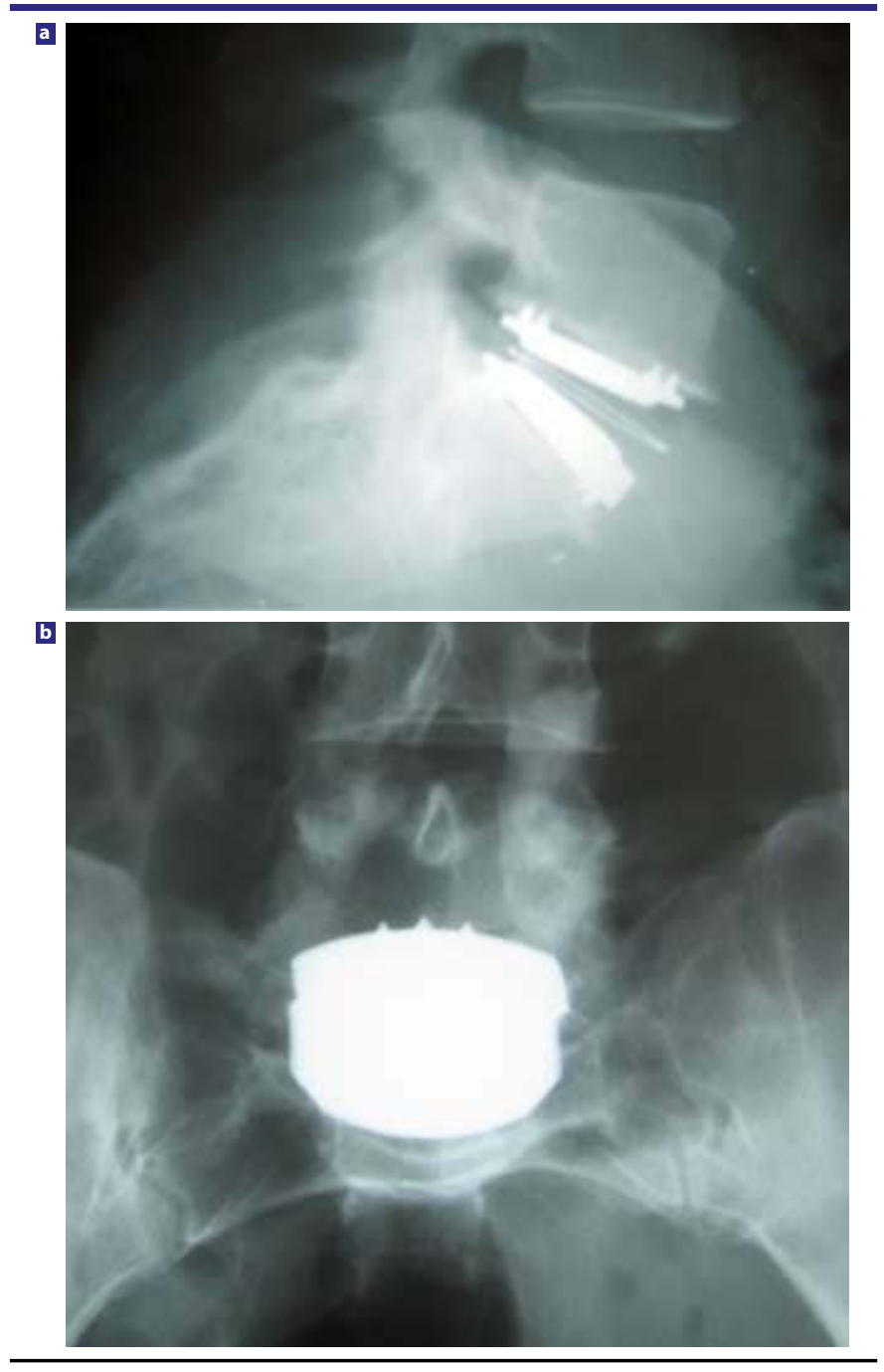

(a) Lateral and (b) anteroposterior postoperative lumbar x-rays showing proper positioning of the SB Charité III at the L5-S1 level.
Postoperatively, the patient had excellent relief of her left lower extremity symptoms and was discharged home one day after the surgery. However, several weeks later, the pain began to recur. Because the patient's initial improvement indicated that her symptoms were reversible, and because nerve root compression was identified intraoperatively, the patient elected for reexploration with partial facetectomy and posterior dynamic stabilization.

\section{Operation}

Via the posterior midline approach, the L5-S1 region was reexposed. Under microscopic imaging, the previous foraminotomy was isolated, and the nerve root was identified. Subsequently all residual compression was removed from scar tissue and synovial fragments, and the partial facetectomy was completed with a high-speed burr. Under lateral and anteroposterior fluoroscopic visualization, the $45 \mathrm{~mm}$ long $\mathrm{x}$ $7 \mathrm{~mm}$ wide Protex screws (Globus Medical Inc., Phoenixville, Pennsylvania) were inserted in the pedicles of L5 and S1 bilaterally. An AccuFlex dynamic titanium rod (Globus Medical Inc., Phoenixville, Pennsylvania) was used to connect the L5S1 screws bilaterally, and the screws were tightened with an end cap. Before closure, the nerve root was confirmed to be free of residual compression. Blood loss was minimal, and the patient tolerated the procedure well, with no significant changes noted on electromyography throughout the surgery.

\section{Postoperative Course}

Immediately after surgery, the patient had complete relief of her lower extremity symptoms. She is now three months in her postoperative course and is still free from her radicular pain. Follow-up radiographs of her lumbar spine show a $6^{\circ}$ range of motion preservation in flexion and extension at three months (Figure 3).

\section{DISCUSSION}

Recognizing the lumbar motion segment unit as a threejoint complex, consisting of an intervertebral disc and two facet joints, was one of the key observations that helped to reduce complications associated with total disc arthroplasty. van Ooij et al. ${ }^{19}$ reported on 27 patients who failed Charité disc replacement. Among the 27 patients in this group who complained of persistent pain, in $11(41 \%)$ of them the pain was thought to be due to facet degeneration. Thus, disc replacement failure due to facet degeneration was a non-negligible cause of pain. However, no preoperative imaging was available to determine if degeneration was evident prior to arthroplasty. Failure in recognizing possible facet disease on preoperative testing might have led to postoperative L5 left radicular pain secondary to compression of the L5-S1 foramen.

Salvage procedures reported in the literature have included posterior facetectomy with posterolateral or $360^{\circ}$ instrumented fusion. ${ }^{20-22}$ The most commonly reported salvage technique is posterolateral lumbar fusion, which has been performed in $1.1 \%$ 


\section{Figure 3}

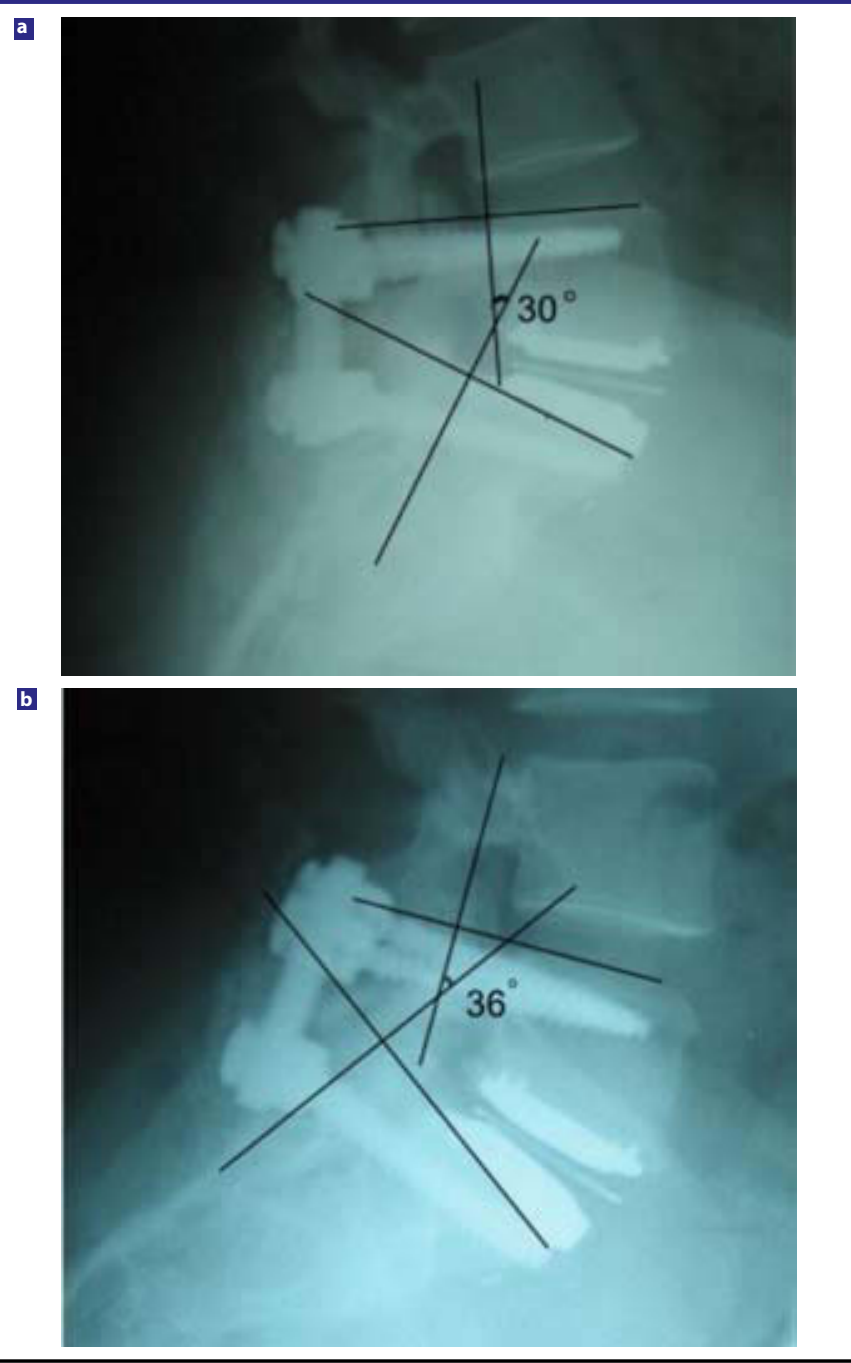

Lateral view of the lumbar spine showing a $6^{\circ}$ range of motion in (a) extension and (b) flexion following posterior dynamic stabilization with titanium rods in the presence of a previously implanted Charité disc.

to $17.4 \%$ of patients receiving the SB Charite III and $1.9 \%$ to $7.8 \%$ for patients receiving the Prodisc II device. ${ }^{20}$ As with any other secondary spinal fusion procedure, the clinical outcomes of fusion following arthroplasty are less than optimal. ${ }^{19,20}$

However, very few authors have discussed the option of posterior dynamic stabilization (PDS) in SB Charité III artificial disc cases as a posterior salvaging procedure. Recent reports have described the potential role of PDS technology, with applications including revision surgery for disc arthroplasty failure due to under-recognized preexisting facet arthropathy, joint disease developing secondary to stresses created by the arthroplasty device itself, or segmental instability secondary to suboptimal placement of the prosthesis. ${ }^{23,24}$ In this case report, the rationale was not to correct the failure of the Charite device but rather to resolve the radicular symptoms secondary to possible facet disease.
This technology may prove to be effective in other instances besides maintaining motion following a posterior disc arthroplasty salvaging procedure. Another potential use of this approach is to augment total disc arthroplasty for complete functional spine unit reconstruction in patients having both disc and facet disease. Because facet disease remains a contraindication to disc arthroplasty, combining both technologies in a $360^{\circ}$ circumferential motion segment reconstruction would allow a broader application of these motion-preserving devices. Huang et al. ${ }^{25}$ using strict criteria, found that only $5 \%$ of the patients considered for surgical intervention in their practice would be candidates for lumbar arthroplasty. ${ }^{20}$ Preexisting facet disease may have led to artificial disc replacement failure in a significant number of patients.

One of the major drawbacks of this case report is lack of long-term follow-up. The consequences of persistent motion controlled by a pedicle screw-based titanium spiral cut rod are unknown, but cyclic fatigue over decades of lumbar flexion, extension, and rotation are likely to result in a high rate of rod fracture or pedicle screw loosening. Although the U.S. Food and Drug Administration is considering several of these devices for investigational exemption, none of these trials have evaluated their use in total disc arthroplasty revision, and none of these trials have been designed to study the ideal posterior dynamic device to be used in this situation.

Disc arthroplasty is a promising technology because it maintains intervertebral spinal motion and reduces the likelihood of adjacent segment degeneration. However, failure in recognizing some degree of preoperative facet degeneration can lead to unsuccessful outcomes. Posterior motion-preserving technologies may be viable for salvage in selected patients because this approach avoids the need to fuse the failed total disc replacement segment.

Paul Khoueir, MD, and Michael Y. Wang, MD

Michael Y. Wang, MD, Department of Neurological Surgery, Miller School of Medicine, University of Miami, Miami, Florida

Paul Khoueir, MD, Department of Neurological Surgery, Université de Montréal, Montréal, Canada

Address correspondence and reprint requests to Paul Khoueir, MD, 8893 St-Hubert Street, Montréal (Québec), Canada H2M 2K8 (email:khoueir@hotmail.com)

This manuscript was submitted August 19, 2007 and accepted for publication on October 8, 2007

\section{REFERENCES:}

1. Bao QB, McCullen GM, Higham PA, Dumbleton JH, Yuan HA. The artificial disc: theory, design and materials. Biomaterials. 1996;17(12):1157-1167.

2. Goel VK, Grauer JN, Patel T, et al. Effects of charité artificial disc on the implanted and adjacent spinal segments mechanics using a hybrid testing protocol. Spine. 2005;30(24):2755-2764. 
3. Anderson PA, Rouleau JP. Intervertebral disc arthroplasty. Spine. 2004;29(23):2779-2786.

4. Bridwell KH, Anderson PA, Boden SD, Vaccaro AR, Wang JC. What's new in spine surgery. J Bone Joint Surg Am. 2006;88(8):1897-1907.

5. Tropiano P, Huang RC, Girardi FP, Cammisa FP, Jr., Marnay T. Lumbar total disc replacement. Surgical technique. J Bone Joint Surg Am. 2006;88(Suppl 1 Pt 1):50-64.

6. Frelinghuysen P, Huang RC, Girardi FP, Cammisa FP, Jr. Lumbar total disc replacement part I: rationale, biomechanics, and implant types. Orthop Clin North Am. 2005;36(3):293-299.

7. Huang RC, Girardi FP, Lim MR, Cammisa FP, Jr. Advantages and disadvantages of nonfusion technology in spine surgery. Orthop Clin North Am. 2005;36(3):263-269.

8. Zigler JE, Anderson PA, Boden SD, Bridwell KH, Vaccaro AR. What's new in spine surgery. J Bone Joint Surg Am. 2003;85-A(8):1626-1636.

9. Lee CK, Goel VK. Artificial disc prosthesis: design concepts and criteria. Spine J. 2004;4(6 Suppl):209S-218S.

10. McAfee PC, Geisler FH, Saiedy SS, et al. Revisability of the CHARITÉ artificial disc replacement: analysis of 688 patients enrolled in the U.S. IDE study of the CHARITÉ Artificial Disc. Spine. 2006;31(11):12171226 .

11. Cinotti G, David T, Postacchini F. Results of disc prosthesis after a minimum follow-up period of 2 years. Spine. 1996;21(8):995-1000.

12. Griffith SL, Shelokov AP, Buttner-Janz K, LeMaire JP, Zeegers WS. A multicenter retrospective study of the clinical results of the LINK SB Charité intervertebral prosthesis. The initial European experience. Spine. 1994;19(16):1842-1849.

13. Zeegers WS, Bohnen LM, Laaper M, Verhaegen MJ. Artificial disc replacement with the modular type SB Charité III: 2-year results in 50 prospectively studied patients. Eur Spine J. 1999;8(3):210-217.

14. Guyer RD, Ohnmeiss DD. Intervertebral disc prostheses. Spine. 2003;28(15 Suppl):S15-S23.

15. Blumenthal S, McAfee PC, Guyer RD, et al. A prospective, randomized, multicenter Food and Drug Administration investigational device exemptions study of lumbar total disc replacement with the CHARITÉ artificial disc versus lumbar fusion: part I: evaluation of clinical outcomes. Spine. 2005;30(14):1565-1575; discussion E1387-E1591.

16. McAfee PC, Cunningham B, Holsapple G, et al. A prospective, randomized, multicenter Food and Drug Administration investigational device exemption study of lumbar total disc replacement with the CHARITÉ artificial disc versus lumbar fusion: part II: evaluation of radiographic outcomes and correlation of surgical technique accuracy with clinical outcomes. Spine. 2005;30(14):1576-1583; discussion E1388-E1590.

17. McAfee PC, Fedder IL, Saiedy S, Shucosky EM, Cunningham BW. SB Charité disc replacement: report of 60 prospective randomized cases in a US center. J Spinal Disord Tech. 2003;16(4):424-433.

18. Guyer RD, McAfee PC, Hochschuler SH, et al. Prospective randomized study of the Charité artificial disc: data from two investigational centers. Spine J. 2004;4(6 Suppl):252S-259S.

19. van Ooij A, Oner FC, Verbout AJ. Complications of artificial disc replacement: a report of 27 patients with the SB Charité disc. J Spinal Disord Tech. 2003;16(4):369-383.

20. German JW, Foley KT. Disc arthroplasty in the management of the painful lumbar motion segment. Spine. 2005;30(16 Suppl):S60-S67.
21. Kostuik JP. Complications and surgical revision for failed disc arthroplasty. Spine J. 2004;4(6 Suppl):289S-291S.

22. Bertagnoli R, Zigler J, Karg A, Voigt S. Complications and strategies for revision surgery in total disc replacement. Orthop Clin North Am. 2005;36(3):389-395.

23. Scott-Young M. Posterior dynamic stabilization devices in the coming age of lumbar disc replacement. Neurosurg Focus. 2007;22(1):E14.

24. Khoueir P, Kim KM, Wang MY. Classification of Posterior Dynamic Devices. Neurosurg Focus. 2007;22(1):E3.

25. Huang RC, Lim MR, Girardi FP, Cammisa FP, Jr. The prevalence of contraindications to total disc replacement in a cohort of lumbar surgical patients. Spine. Nov 15 2004;29(22):2538-2541. 